\title{
Prevalence of antibodies to human $T$ cell leukaemia/lymphoma virus in blood donors in north London
}

\author{
M Brennan, J Runganga, J A J Barbara, M Contreras, R S Tedder, J A Garson, P W Tuke, \\ P P Mortimer, L McAlpine, J H C Tosswill
}

\begin{abstract}
Objectives-To determine the prevalence of antibodies to the human $T$ cell leukaemia/lymphoma viruses (HTLV-I and HTLV-II) in blood donors in north London in order to assess the economic impact and the logistic effects that routine screening would have on the blood supply.
\end{abstract}

Design-All donations collected by the north London blood transfusion centre between January 1991 and June 1991 were screened for antibodies to HTLV-I and HTLV-II by modified, improved Fujirebio gel particle agglutination test. Positive samples were titrated and retested as necessary.

Subjects-96720 unpaid volunteers, who gave 105730 consecutive donations of blood and plasma.

Setting-North London blood transfusion centre.

Main outcome measure-Observed numbers of donors confirmed to be seropositive for HTLV by reference laboratories.

Results-Of $2622(2 \cdot 5 \%)$ initially reactive samples, $414(0.4 \%$ of all samples) gave a titre of $\geqslant 1$ in 16 on the modified agglutination test. Thirty five of the 414 serum samples yielded positive results on one of two enzyme linked immunosorbent assays (ELISA (Cambridge Biotech and Abbot)), and none of these results were confirmed by either reference laboratory. Five samples yielded positive results on both ELISAs and all five of these were confirmed to contain antibodies to HTLV. One of the five contained antibodies to HTLV-II and the others antibodies to HTLV-I. Four seropositive donors were white women whose only risk factor for infection was sexual contact. The fifth (positive for antibodies to HTLV-II) was an Anglo-Caribbean man who admitted to previous misuse of intravenous drugs.

Conclusion-The prevalence of antibodies to HTLV in blood donors in north London was one in $19344(0 \cdot 005 \%)$. Up to 100 donors a year might be identified in the United Kingdom as being infected with HTLV, although prevalence in different regions may vary considerably.

\section{Introduction}

Although several infectious diseases are transmissible by blood transfusion, HIV has been the main focus of public and scientific concern over the past 10 years. Education of donors and self exclusion, careful selection of donors, screening of blood donations, and procedures for inactivation of viruses in blood products have now become routine in developed countries. Despite these effective measures there is still considerable public anxiety about the safety of blood and its derivatives. The known existence of other human viruses with a potential for transmission by transfusion has exacerbated this anxiety. The human T-cell leukaemia/lymphoma virus type I (HTLV-I) is one of these viruses, as is the closely related human $\mathrm{T}$ cell leukaemia/lymphoma virus type II (HTLV-II). ${ }^{1}$

In 1980 HTLV-I, the first human retrovirus to be described, was identified. It is endemic in Japan, the Caribbean, the south eastern United States, and parts of Africa. Seroprevalence varies between and within endemic areas. As many as $15 \%$ of the population in some areas of southwest Japan have antibodies to HTLV in their serum, and seroprevalence in the Caribbean is reported to be between $1 \%$ and $4 \%$. Although the seroprevalence in non-endemic areas is low, infections with HTLV-I have been identified in immigrants from endemic areas. ${ }^{2}$

HTLV-I is transmitted and maintained in the population by sexual intercourse, breast feeding, misuse of intravenous drugs, and, less commonly, by blood transfusion. ${ }^{3}$ The epidemiology of HTLV-II is less certain but is probably similar. In areas of low endemicity infection with both HTLV-I and HTLV-II has been associated with blood transfusion ${ }^{4}$ and parenteral drug use. ${ }^{5}$ HTLV-I is an intracellular virus; it is transmitted by both whole blood and cellular blood components but rarely by fresh plasma and not at all by plasma products. ${ }^{6}$ Rates of seroconversion of between $50 \%$ and $80 \%$ have been recorded in recipients of seropositive whole blood, red cell concentrates, and platelets. Transmission is more likely if blood components are fresh. ${ }^{7}$

It is now established that HTLV-I is associated with at least two diseases: an aggressive malignancy (adult $\mathrm{T}$ cell leukaemia/lymphoma) and a chronic neurological disorder (tropical spastic paraparesis, also called HTLV associated myelopathy). Adult T cell leukaemia/lymphoma appears after a characteristically long latent period, usually decades after the infection. The incubation period for neurological disease may be shorter, sometimes three to five years or less. ${ }^{8}$ Both adult $T$ cell leukaemia/lymphoma and tropical spastic paraparesis have been reported in the United Kingdom. ${ }^{9}$ Most people infected with the virus remain healthy with an estimated $2-5 \%$ lifetime risk of developing the haematological complication. ${ }^{10}$ The attack rate for tropical spastic paraparesis may be even lower, probably in the region of $0.25 \%$ per lifetime for infected people. ${ }^{11} \mathrm{~A}$ wider spectrum of clinical morbidity may be encountered, and there may be hitherto unidentified mortality associated with HTLV. Adult $\mathrm{T}$ cell leukaemia/lymphoma after transfusion of blood infected with HTLV has only rarely been convincingly shown, ${ }^{12}$ whereas tropical spastic paraparesis as a result of transfusion has been well documented. ${ }^{8}$ HTLV-II may also be associated with lymphoma ${ }^{13}$ and with cases of chronic neurological disease. ${ }^{14}$ 
Routine screening of all blood donations for HTLV - antibodies was introduced in the United States in late 1988 and shortly thereafter in Canada. During the first nine months of testing in the United States the seroprevalence was approximately $0.017 \%$ (C T Fang, A E Williams, S G Sandler, third annual retrovirology conference, Hawaii, 1990). Most (52\%) seropositive donors in the United States are confirmed to be positive for antibodies to HTLV-II. ${ }^{15}$ In France, however, where routine screening was introduced in 1991, the seroprevalence is lower $(0.004 \%)$, and only $1.5 \%$ of seropositive donors have HTLV-II infection. ${ }^{16}$

A small survey of the seroprevalence of HTLV performed at the North London Blood Transfusion Centre in 1989 detected no confirmed positive samples in 5000 unselected samples from donors. On the other hand, serum samples from two out of 2376 AfroCaribbean donors at the centre were confirmed to be positive for HTLV antibodies. ${ }^{17}$ Before deciding whether to introduce routine screening of donors in the United Kingdom it would be important to know the overall prevalence of HTLV antibodies. The economic impact and the logistical effects that screening would have on the blood supply could also then be ascertained.

\section{Methods}

Between 2 January and 30 June 1991 all blood and plasma donations collected by the transfusion centre were screened for HTLV antibodies by a modification of the gelatin particle agglutination test by using improved reagents from the manufacturer (Fujirebio, Japan). ${ }^{18}{ }^{19}$ Provided that all the usual selection criteria for donors were met, donations negative for antiHTLV by the agglutination test were available for issue to hospitals.

The modified test had been previously validated by using well characterised seropositive samples and shown to be highly sensitive in detecting antibodies to HTLV (unpublished data). Samples with a specific titre greater than or equal to 1 in 16 underwent secondary testing in duplicate by two enzyme linked immunosorbent assays (ELISA) in accordance with manufacturers' instructions. Samples which tested positive in at least one of these assays were referred to two reference laboratories (division of virology, University College London medical school, and the virus reference division, Central Public Health Laboratory) for confirmatory testing, together with whole blood samples suitable for amplification of virus DNA by the polymerase chain reaction. The following confirmatory tests were performed on the referred samples: in house competitive ELISA (COMPEIA, University College London medical school) and in house competitive radioimmunoassay (COMPRIA, Central Public Health Laboratory); commercially available ELISAs with synthetic peptide antigens to type samples as containing HTLV-I or HTLV-II antibodies (Synth enzyme immunosorbent assay, UBI, and Select enzyme immunosorbent assay, IAF Biochem); western blots based on viral lysate (Dupont and Fujirebio) and on viral lysate enhanced with recombinant $e n v$ protein p21e (Cambridge Biotech). Selected samples were tested by the polymerase chain reaction at University College London medical school by using tax/rex primers ${ }^{20}$ and at the central public health laboratory by using generic HTLV primers SK $110 / 111$ derived from the pol region of the virus. ${ }^{21}$

Donors confirmed as positive were contacted by letter and asked to attend the transfusion centre. When donors were interviewed a medical history was taken, and they were counselled. With their permission a further blood sample was obtained. Donors were offered referral to a specialist and, if relevant, family testing.

\section{Results}

A total of 105730 consecutive donations of blood and plasma collected between January and June 1991 were screened for HTLV antibodies. This was equivalent to testing 96720 individual donors because of duplicate testing of some plasma donors. In total, 2622 samples $(2.48 \%)$ were initially reactive on the modified agglutination test (including those with minimal reactivity). Of these, $414(0.4 \%)$ samples had a specific titre of 1 in 16 or greater and underwent secondary testing in duplicate by each ELISA (table I). Five

TABLE I-Summary of results of tests for HTLV antibodies among blood donors

\begin{tabular}{lcc}
\hline & $\begin{array}{c}\text { No of } \\
\text { samples } \\
\text { tested }\end{array}$ & $\begin{array}{c}\text { Reactive } \\
\text { rate (\%) }\end{array}$ \\
\hline Testing sequence & 96720 & \\
\hline $\begin{array}{l}\text { Donor samples screened } \\
\text { Samples initially reactive by modified gel } \\
\text { particle agglutination test }\end{array}$ & 2622 & 1 in $40(2 \cdot 48)$ \\
$\begin{array}{l}\text { Samples with a specific titre } \geqslant 1 \text { in } 16 \text { by } \\
\text { modified gel particle agglutination test }\end{array}$ & 414 & 1 in $225(0.4)$ \\
$\begin{array}{l}\text { Samples reactive by Abbott ELISA only } \\
\text { Samples reactive by Cambridge Biotech } \\
\quad \text { ELISA only }\end{array}$ & 35 & \\
$\begin{array}{l}\text { Samples with "grey area" results } \\
\text { Samples reactive by both ELISAs }\end{array}$ & 0 & \\
& 4 & 1 in $20000(0.005)$ \\
\hline
\end{tabular}

samples were positive by both ELISAs. There were 35 additional samples which were positive by Abbott ELISA and negative by Cambridge Biotech ELISA. All of these 35 were reactive for gag by western blotting based on viral lysate alone but none showed reactivity with p21e in western blotting. They were also negative for HTLV by the polymerase chain reaction. No samples were reactive by Cambridge Biotech ELISA alone. Four samples were reactive in the "grey area" (three by Abbott ELISA and one by Cambridge Biotech ELISA), two of which were reactive for gag only by western blotting. No other reactivity was found in these four samples, which were confirmed to be negative from the results of the polymerase chain reaction.

A total of 44 samples were referred to the two reference laboratories for confirmatory testing. Both laboratories independently confirmed the five serum samples which had been reactive in both ELISAs as positive for HTLV antibodies. These five donors had antibodies to both gag and env gene products on western blotting, consistent with World Health Organisation criteria for seropositivity. ${ }^{22}$ In one of these donors, however, antibodies to env could be shown only by using p21e enhanced western blotting (Cambridge Biotech). By using the polymerase chain reaction, enhanced regions of the HTLV-I or HTLV-II genome could be amplified from mononuclear cells from peripheral blood of all five donors.

None of the 39 other referred samples was confirmed as positive but one sample was classed as indeterminate by one reference laboratory, though negative by the other. This sample had been reactive on only the Abbott ELISA. Subsequently a fresh blood sample was obtained from this donor and was found to be negative from the results of the polymerase chain reaction.

Four of the five donors were found to have antibodies to HTLV-I and one antibodies to HTLV-II. Differentiation of HTLV-I and HTLV-II by the polymerase chain reaction and by the two ELISAs (Synth and Select) was completely confirmed by one reference laboratory. In the other, four of the 39 serum samples negative for the polymerase chain reaction were reactive in the discriminatory ELISAs (fig).

All five donors confirmed to be seropositive were counselled, and results on fresh samples were all consistent with initial findings. Table II summarises 


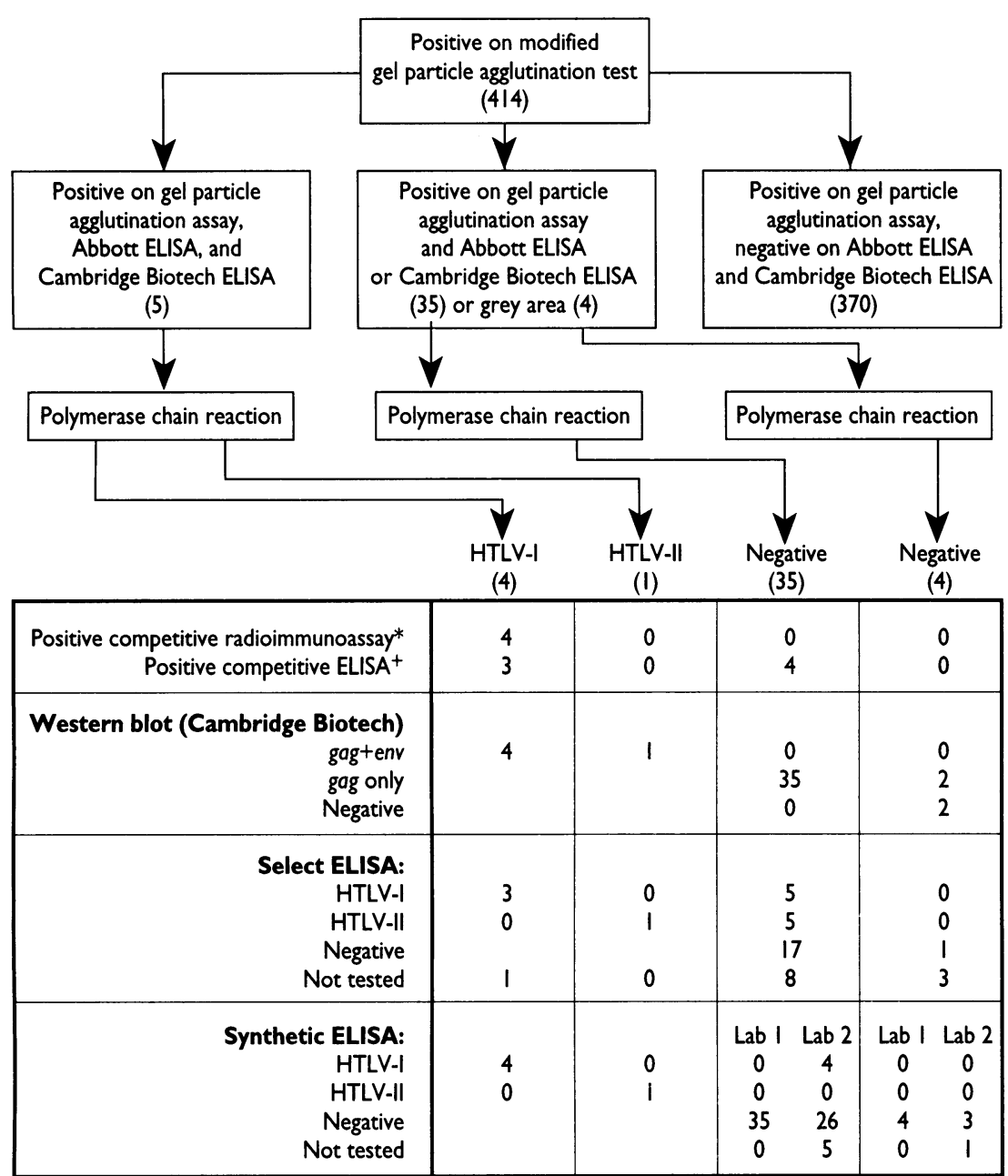

* In house Central Public Health Laboratory

+ In house University College London Medical School

Details of system used for testing serum samples from blood donors for HTLV antibodies

the characteristics of donors found to be seropositive. Four were white women. On detailed questioning their only risk factors for contracting HTLV seemed to be sexual contact with their West Indian partners in two cases (1 and 3) and with an Iranian in the third case (4). A fourth donor (2) showed evidence of recent seroconversion as indicated by a distinct rise in antibody titre in a second sample collected three months later. This was consistent with the donor having started a sexual relationship three months before donating. Her Chinese partner was subsequently shown to be positive for antibodies to HTLV-I. The fifth donor (5) was an Anglo-Caribbean man aged 31 whose serum was confirmed to contain HTLV-II antibodies. He gave a history of misuse of intravenous drugs with needle sharing 13 years previously in the United Kingdom. His serum was also positive for antibodies to hepatitis $C$ virus (with viraemia shown in the polymerase chain reaction), and he had antibody to hepatitis $B$ core antigen.

TABLE II-Characteristics of blood donors confirmed to be positive for HTLV antibodies

\begin{tabular}{|c|c|c|c|c|c|}
\hline Donor & Sex & $\begin{array}{c}\text { Age } \\
\text { (years) }\end{array}$ & $\begin{array}{c}\text { HTLV } \\
\text { type }\end{array}$ & Race & Probable route of transmission \\
\hline 1 & F & 56 & I & White & $\begin{array}{l}\text { Sexual contact over past } 30 \text { years with West Indian } \\
\text { husband. No other risk factors }\end{array}$ \\
\hline 2 & $\mathbf{F}$ & 42 & I & White & $\begin{array}{l}\text { Evidence of recent seroconversion. Sexual contact for } 3 \text { months } \\
\text { before donating with Chinese man seropositive for HTLV-I. No } \\
\text { other risk factors }\end{array}$ \\
\hline 3 & F & 34 & I & White & $\begin{array}{l}\text { Sexual contact with West Indian partner 1978-79. No other risk } \\
\text { factor }\end{array}$ \\
\hline 4 & F & 45 & I & White & Sexual contact with Iranian husband for 10 years \\
\hline 5 & $\mathbf{M}$ & 31 & II & $\begin{array}{l}\text { Anglo- } \\
\text { Caribbean }\end{array}$ & $\begin{array}{l}\text { Intravenous drug use } 13 \text { years previously in London. (Also } \\
\text { confirmed positive for antibodies to hepatitis C virus and } \\
\text { hepatitis B core antigen) }\end{array}$ \\
\hline
\end{tabular}

\section{Discussion}

The prevalence of antibodies to HTLV in blood donors in north London is about one in 20000 compared with a rate of one in 6000 in North American blood donors. ${ }^{15}$ This implies that if routine screening for HTLV antibodies were introduced in the United Kingdom up to 100 donors might be expected to be confirmed positive for HTLV in the first year of screening. In reality the prevalence of these antibodies in the rest of the country may well be lower, paralleling the results in France, where an identical seroprevalence of antibodies to HTLV was found but restricted to metropolitan areas. ${ }^{23}$

Our large scale study has shown that it would be difficult to specify groups for selective donor screening. Selective screening for HTLV antibodies based on ethnic origin would have detected only one of the five confirmed donors, a 31 year old Anglo-Caribbean man. Moreover, his ethnic origin did not prove predictive of HTLV-I infection, as he was shown to be infected with HTLV-II, presumably associated with his history of misuse of intravenous drugs. He was also a carrier of hepatitis $C$ virus and had previously been infected with hepatitis B virus. He had not admitted to misuse of intravenous drugs in the confidential questionnaire completed by all donors at the transfusion centre.

Two infected donors (1 and 3) would have been preselected for screening only if a detailed sexual history had been obtained. Donor 1 had been married to an Afro-Caribbean man for the past 30 years, and donor $\mathrm{C}$ had had a West Indian sexual partner between 1978 and 1979. A potential risk of HTLV infection would have been very difficult to identify in the remaining two donors infected with HTLV, one of whom (donor 4) had been married to an Iranian man for 10 years. Although HTLV has been described in Jewish emigrants from northern Iran, ${ }^{24}$ this donor's husband was not a Jew. No other risk factors for HTLV seroconversion were elicited from these four women. The finding that the four infected women had probably acquired HTLV infection through sexual intercourse is consistent with the observation previously reported that male to female transmission is more efficient than female to male. ${ }^{1}$ Our study shows that in the United Kingdom selective screening for HTLV based solely on ethnic origin would probably be ineffective.

\section{FEASIBILITY OF SCREENINC}

When considering the introduction of a new test for the microbiological screening of blood donations, the basis for the decision should be defined as carefully as possible. The extent of disease prevented by screening and the cost of doing so must be estimated. The prevalence of infection in blood donors, the rate of transmission by infected blood donors, and the level of expression of the infection as disease in recipients need to be balanced against the increased complexity and costs of screening, confirmatory testing, counselling, and recruitment of replacement donors.

Our observed prevalence of antibodies to HTLV of one in 20000 is a much lower carrier rate than that for hepatitis B and C viruses (about one in 1500 new donors) but is similar to that of antibodies to HIV-1 and HIV-2 in new donors (one in 23000 ). Morbidity in HTLV infection, however, is far less common than in HIV infection ( $<5 \% v>50 \%$ lifetime risk).

Studies on the rate of HTLV-I infection in recipients receiving infected blood have shown that up to $70 \%$ of recipients of cellular blood components will seroconvert. In addition, the number of days that blood is stored before transfusion is inversely related to the proportion of seroconversions in recipients. In one study $79.2 \%$ of recipients of blood stored for 1-5 days seroconverted, compared with $63.6 \%$ and 
$55 \%$ after storage for 6-10 and 11-16 days, respectively. ${ }^{1}$

Relatively few cases of HTLV-I disease associated with transfusion have been reported and these have nearly all been cases of tropical spastic paraparesis. The usually protracted incubation period between infection with HTLV-I and onset of symptoms makes it difficult to establish a causal relation with transfusion, but there have also been reports of accelerated development of tropical spastic paraparesis in recipients of infected blood components after short intervals: 18 weeks in one case and six months in another. ${ }^{8}$ It has been estimated that for HTLV-I seropositive subjects the lifetime risks of adult $\mathrm{T}$ cell leukaemia/lymphoma and of tropical spastic paraparesis are in the order of $2-4 \%{ }^{2}$ and $0 \cdot 25 \%,{ }^{11}$ respectively. Given that the NHS has limited financial resources it is essential to attempt a cost-benefit analysis of the impact of routine screening for HTLV antibodies. In the United Kingdom, if up to 100 donors positive for anti-HTLV give blood in one year, a maximum of 200 cellular components positive for anti-HTLV could potentially be transfused each year (though probably some $10 \%$ would not be transfused). If about $70 \%$ of recipients seroconverted for HTLV antibodies there would be 140 infections arising from transfusion annually in the United Kingdom. Since the combined lifetime risk of adult $T$ cell leukaemia/lymphoma and tropical spastic paraparesis is probably less than $5 \%$, every year up to six people may be put at risk of developing HTLV associated disease in their lifetime. In practice fewer are at risk as half the blood is transfused into patients who die within one year. Thus if routine screening of all donations for antibodies were introduced the direct impact on disease prevention would be very small, although secondary infections in the sexual partners or breast fed infants of infected donors and recipients of transfusions would also be preventable.

\section{COSTS OF SCREENING}

Reagent costs for routine testing for anti-HTLV in the United Kingdom with currently available ELISAs would be in the region of $£ 2 \mathrm{~m}$ a year. Confirmatory testing would be required for between $0.2 \%$ and $0.3 \%$ of donations, and these would be unavailable for transfusion. The minimum cost of preventing a single transmission related to transfusion is about $£ 30000$ and for preventing the risk of HTLV associated disease developing in a recipient's lifetime, $£ 1.3 \mathrm{~m}$. We acknowledge that in the absence of more clinical data to predict the illness caused by HTLV infection in a Western population these are tentative projections but even so they provide some idea of the impact of screening.

Counselling of donors positive for HTLV was not straightforward. The concept of a latent virus that will probably be inapparent throughout the person's life had to be explained. Its transmissibility to children and sexual partners and the small risk for the development of acute leukaemia or paralysis also had to be discussed. It was helpful to be able to refer positive donors to a clinical specialist with an interest in retrovirus infections since most general practitioners in the United Kingdom have little experience of HTLV infection.

In the light of these results can we justify screening for HTLV? If not, can we defend a decision not to screen in the face of the Consumer Protection Act and product liability? The fact that routine screening for HTLV is occurring in the United States, Japan, and some European countries is bound to have a bearing on practice in Europe and on the decision in the United Kingdom.

Finally, if routine screening were to be introduced there would be the options of using an assay for HTLV-I and HTLV-II antibodies or a combined

\section{Public health implications}

- HTLV-I and HTLV-II are transmissible by transfusion of cellular blood components, and screening of blood donations for antibodies to the viruses is mandatory in certain countries

- In most cases there are no clinical manifestations of infection with HTLV

- In blood donors in north London the prevalence of antibodies to HTLV is one in 20000 ; $80 \%$ are to HTLV-I

- Screening selected (ethnic minority) donors would be ineffective for excluding potentially infectious units

- A cost-benefit analysis of screening for HTLV infection is difficult to define

ELISA for the two antibodies and antibodies to HIV-1 and HIV-2 to choose from. The sensitivity of one such ELISA seems to be good, ${ }^{25}$ but the specificity seems to be poor (unpublished data). Combined testing has the advantage that there is little additional work in the laboratory with no need for extra staff, but all testing strategies require confirmatory assays and viral speciation, the counselling of donors, and, if possible, a procedure for restoring donors with false positive results to the panel. Alternatively, it may be a more effective use of resources to provide cellular blood components seronegative for HTLV only for those recipients most at risk of developing disease-that is, fetuses, newborn infants, and children (who have a longer life expectancy than most patients receiving blood) and immunosuppressed patients. Such components could be obtained from a fairly small panel of screened blood donors, or leucodepletion of cellular components may prove to be effective in preventing transmission of HTLV.

The above considerations show the complexity of the decision pathway associated with the question of whether or not to screen blood donors for antibodies to HTLV. Many factors have to be taken into account to optimise the accuracy of the calculations. Data on several factors are often sparse. With the low prevalence of HTLV in the United Kingdom, small changes in the ethnic composition of the donor population under study might have a considerable impact on the estimate of seroprevalence.

We thank the Department of Health for funding this project, Mrs J Mortimer for statistical advice, and Miss Marina Mobed, North London Blood Transfusion Centre, for excellent secretarial help.

1 Sandler SG, Fang CT, Williams AE. Human T cell lymphotropic virus type I and II in transfusion medicine. Transfusion Medicine Reviews 1991;2:93-107. 2 Anon. HTLV-I comes of age. Lancet 1988;i:217-9.

3 Tajima K, Tomanaga S, Suchi T, Kawagoe T, Komoda H, Hinuma Y. Epidemiological analysis of the distribution of antibody to adult T-cell leukaemia virus. Fapanese fournal of Cancer Research 1982;73:893-901.

4 Minamoto GY, Gold JWM, Scheinberg DA, Hardy WD, Chein N, Zukerman E. Infection with human T-cell leukaemia virus type $I$ in patients with E. Infection with human T-cell leukaem
leukaemia. N Engl f Med 1988;318:219-22.

5 Lee H, Swanson P, Shorty VS, Zack JA, Rosenblatt JD, Chen ISY. High rate of HTLV-II infection in seropositive IV drug abusers from New Orleans. of HTLV-II infection
Science $1989 ; 244: 471$.

6 Cannavaggio M, Leckie G, Allain J-P, Steaffens JW, Laurian Y, Brettler D, et al. The prevalence of antibody to HTLVI/II in United States plasma donors and in United States and French haemophiliacs. Transfusion 1990;30:780-2.

7 Okochi K, Sato H, Hinuma Y. A retrospective study on transmission of adult $\mathrm{T}$ cell leukaemia virus by blood transfusion: seroconversion in recipients. Vox Sang 1984;46:245-53.

8 Osame AM, Izumo S, Igata A, Matsumoto M, Matsumoto T, Sonoda S. Blood transfusion and HTLV-I associated myelopathy. Lancet 1986;ii:104-5.

9 Toswill J, Parry J. HTLV-I in English patients. Lancet 1989;ii:328.

10 Murphy EL, Hanchard B, Figueroa JP, Gibbs WN, Lofters WS, Campbell M, et al. Modelling the risk of adult T-cell leukaemia/lymphoma in persons et al. Modelling the risk of adult T-cell leukaemia/ymphoma in persons
infected with human T-lymphotropic virus type I. Int $f$ Cancer 1989;43: infected

慗


11 Kaplan JE, Osame M, Kubota H, Igata A, Nishitani H, Maeda Y, et al. The risk of development of HTLV-I-associated myelopathy/tropical spastic paraparesis among persons infected with HTLV-I. fournal of Acquired Immune Deficiency Syndromes 1990;3:1096-101.

12 Chen Y-C, Wang C-H, Su I-J, Hu C-Y, Chou M-J, Lee TH, et al. Infection of human T-cell leukaemia virus type 1 and development of human T-cell leukemia/ymphoma in patients with hematologic neoplasma: a possible linkage to blood transfusion. Blood 1989;74: neoplasm

13 Hall WW, Takahashi H, Shi Wei Zhu, Ijichi S. Human T cell leukaemia virus, type II (HTLV-II). In: Neu HC, Levey JA, Weiss RA, eds. Focus on HIV. Edinburgh: Churchill Livingstone, 1993

14 Hjelle B, Appenzeller O, Mills R, Alexander S, Torrez-Martinez N, Jahnke R, et al. Chronic neurodegenerative disease associated with HTLV-II infection. Lancet 1992;339:645-6.

15 Williams AE. HTLV II infection in US blood donors. Transfusion Today 1990;7:5.

16 Pillonel J, Courouce A-M, Brunet J-B, Lemaire J-M, Maniez M. Le depistage du HTLV dans les etablissments de transfusion Sanguine. La gazette de la Transfusion 1993;84:15-7.

17 Salker R, Tosswill JH, Barbara JAJ. HTLV-I/II antibodies in UK Blood donors. Lancet 1990;336:317.

18 Barbara J. Gelatin particle agglutination assay for HIV antibodies: a rapid, economical modification with increased sensitivity. Medical Laboratory Sciences 1989;46:135-40.

19 Fujino $R$, Kuwato $K$, Ikeda $M$, Miyakoshi $H$, Mizukoshi $M$, Imai J. Improvement of gelatin particle agglutination test for detection of antiHTLV-I antibody. Fapanese fournal of Cancer Research 1991;82:367-70.

20 Tuke PW, Luton P, Garson JA. Differential diagnosis of HTLV-I and HTLV-II infections by restriction enzyme analysis of "nested" PCR products. 7 Virol Meth 1992;40:163-74.

21 Erlich G, Greenberg S, Abbott M, eds. PCR protocols: a guide to methods and applications. Oxford: Academic Press, 1990

22 Kiyokawa T, Yamaguchi K, Nishimura Y, Fukuoka N, Watanabe T, Takatsuki K. Western blot criteria for HTLV-I. Lancet 1991;338:312

23 Couroucé A-M, Pillonel J, Lemaire J-M, Maniez M, Brunet J-B. Seroepidemiology of HTLV-I/II in universal screening of blood donations in France. AIDS 1993;7:841-7.

24 Meytes D, Schochat B, Lee H, Nadel G, Sidi Y, Cerney M. Serological and molecular survey for HTLV-I infection in a high-risk Middle Eastern group. Lancet 1990;336:1553-5.

25 McAlpine L, Parry JV, Tosswill JHC. An evaluation of an enzyme immunoassay for the combined detection of antibodies to HIV-1, HIV-2, HTLV-I and HTLV-II. AIDS 1992;6:387-91.

(Accepted 23 August 1993)

\title{
Twins, triplets, and cerebral palsy in births in Western Australia in the 1980s
}

\author{
Beverly Petterson, Karin B Nelson, Linda Watson, Fiona Stanley
}

\begin{abstract}
Objectives-To examine the rate of cerebral palsy in twins and triplets in births from 1980 to 1989 in Western Australia and to identify factors associated with increase in risk.

Design-Pluralities for all births in Western Australia were identified through the standardised midwives' notification system, and cases of cerebral palsy were identified from the Western Australian cerebral palsy register.
\end{abstract}

Main outcome measures-Multiple births, cerebral palsy, excluding postneonatal cause.

Results-The prevalence of cerebral palsy in triplets, of 28 per 1000 survivors to 1 year $(95 \%$ confidence interval 11 to 63 ) exceeded that in twins $(7 \cdot 3 ; 5.2$ to 10$)$ and singletons $(1.6 ; 1.4$ to 1.8$)$. Although twins and triplets were more likely than singletons to be low in birth weight, their risks of cerebral palsy if low in birth weight were similar. In contrast, in normal birthweight categories twins had a higher rate of cerebral palsy $(4 \cdot 2 ; 2 \cdot 2$ to $7 \cdot 7)$ than singletons $(1.1 ; 1.0$ to 1.3$)$. The prevalence of cerebral palsy was similar in twins of unlike sex pairs, all of whom are dizygotic, and in like sex pairs. A twin pair in which one member died in utero was at higher risk of cerebral palsy: 96 per 1000 twin pairs (36 to 218 ) compared with $12(8 \cdot 2$ to 17$)$ for twin pregnancies in which both survived. There was a similar but non-significant trend for death of one triplet to be associated with increased risk of cerebral palsy in the survivors of the set.

Conclusion-Triplet pregnancies produced a child with cerebral palsy 47 times more often than singleton pregnancies did and twin pregnancies eight times more often. Eighty six per cent of cerebral palsy in multiple births was in twins. As multiple births are increasing mainly because of personal and medical decisions the increased risk of cerebral palsy in multiple births is of concern.

\section{Introduction}

In Western Australia, as in the United Kingdom, ${ }^{12}$ the United States, ${ }^{34}$ and elsewhere, ${ }^{56}$ multiple births have increased in recent decades. Between 1980 and 1989 the proportion of twins in Western Australia rose from $1.9 \%$ to $2.9 \%$ and higher order multiple births from $0 \cdot 1 \%$ to $1 \cdot 0 \%$. $^{7}$ Concern has been expressed about the perinatal and longer term complications associated with these increases. ${ }^{124}$

Twins born in Western Australia in 1991 were four times more likely than singletons to be stillborn and five times more likely to die as neonates. ${ }^{7}$ Twins were 16 times more likely than singletons to weigh less than $1500 \mathrm{~g}$ at birth; one in 3.3 liveborn infants weighing under $1500 \mathrm{~g}$ was from a multiple birth. Twins required neonatal intensive care eight times more often than singletons, 21 times more often for longer than 28 days. Comparable figures for triplets are not available in Western Australia but probably the risks and stresses for triplet births are even greater. The problems experienced by parents and medical staff and the costs resulting from the increase in multiple births have been discussed in the lay $^{6}{ }^{8}$ and medical press. ${ }^{2910}$

In addition to their vulnerability to early illness and death, ${ }^{11}$ twins are at higher risk of developing cerebral palsy. ${ }^{1213}$ A previous population based report from Western Australia describing births from 1956 to 1985 observed a prevalence of cerebral palsy in twins 2.6 times that in singletons and found suggestive but, because of small numbers, inconclusive evidence that triplets were at higher risk of cerebral palsy than twins. ${ }^{14}$ We now update that earlier report and further examine the risk of cerebal palsy or of death in multiple births in this population in the decade of the 1980s.

\section{Methods}

Plurality and annual numbers of births and their characteristics including birth weight for the years 1980 to 1989 were obtained from the maternal and child health research database, which includes midwives' notifications of births (a statutory file of all births in the state collected by the health department of Western Australia including stillbirths of at least 20 weeks' gestation or $400 \mathrm{~g}$ birth weight), and linked to birth registrations and deaths to the age of 1 year provided by the registrar general of Western Australia. Population data for years before 1980 were obtained from publications of the Australian Bureau of Statistics $^{15}$ and the health department of Western Australia. ${ }^{16} 17$

Details of cases of cerebral palsy were obtained from the Western Australian cerebral palsy register, an ongoing population based system that uses multiple 